\title{
A Study on Histopathological Patterns of Endometrium in Different Types of Abnormal Uterine Bleeding Among Peri And Postmenopausal Women
}

\author{
Dr. Sonia Gon ${ }^{1,}$ Dr. Tamalika Kundu ${ }^{2,}$ Dr. Debjani Mallick ${ }^{3,}$ \\ Dr. Gayatri Ghosh ${ }^{4}$ \\ ${ }^{1,2,3,4}$ Department Of Pathology, ESIPGIMSR \& ESIC Medical College, Joka,Kolkata,India
}

\begin{abstract}
Introduction: Abnormal uterine bleeding (AUB) is considered as one of the most common problems both to the patient and the gynecologist. Until the pathology underlying atypical uterine bleeding is accurately diagnosed, proper therapy is hardly possible. The objectives of the study were to determine the types and frequencies of pathologies in endometrial curettings of abnormal uterine bleeding \& compare different endometrial pathologies in different types of abnormal uterine bleeding in peri and postmenopausal patients.

Methods: This is a retrospective study, conducted in the Department of Pathology, in a tertiary care teaching hospital, Kolkata from November 2014 to October 2015. All cases of AUB in the peri and postmenopausal patients with a probable endometrial cause were included in the study. Results: A total of 156 cases were analyzed. AUB was most prevalent in the perimenopausal age group. The most common presenting complaint was menorrhagia (43\%). Histopathological diagnosis was not possible in 5 cases with inadequate sample material. Non-organic causes of the endometrium comprised $80.1 \%$ of total while in the rest (19.9\%) definite organic pathology was found. Among the non- organic causes secretory endometrium(42.9\%) and in the organic group polyp(43.3\%) was found to be commonest. Malignancy comprises $23.3 \%$ and hyperplasia constitutes $30 \%$ of total organic causes.

Conclusion: Histopathological diagnosis of hyperplasia and malignancy is maximum in the patients presented with menometrorrhagia followed by postmenopausal bleeding. Hereby Histopathological evaluation of endometrial samples is especially indicated in peri and postmenopausal women to rule out neoplastic and preneoplastic conditions.
\end{abstract}

Keywords: Abnormal uterine bleeding, endometrium, perimenopausal, postmenopausal, carcinoma .

\section{Introduction}

Abnormal Uterine Bleeding (AUB)-a term used to describe any type of bleeding that does not fall within the normal ranges for amount, frequency, duration or cyclicity ${ }^{1}$.It includes both dysfunctional uterine bleeding (DUB) where no demonstrable organic cause is seen and bleeding from structural causes like fibroids, polyps, endometrial carcinoma, and pregnancy complications. Endometrial curettage in such cases plays an important role in excluding organic uterine disorders. ${ }^{2}$

Abnormal uterine bleeding (AUB) is considered as one of the most common and perplexing problems both to the patient and the gynecologist; it is responsible for as many as one-third of all outpatient gynecologic visits. Two and a half million American women complain of a menstrual disorder each year. ${ }^{3}$ Variations from the normal cyclical pattern in the peri-menopausal age may be due to physiological hormonal changes or may be due to neoplastic changes. AUB may be the symptom of endometrial carcinoma in $8-50 \%$ of cases. ${ }^{4}$ The increased risk of endometrial hyperplasia and endometrial carcinoma is more evident in peri-menopausal and post-menopausal women with abnormal uterine bleeding. ${ }^{5}$ Endometrial curettage plays an important role in excluding these organic causes of AUB like endometrial hyperplasia or endometrial carcinoma by allowing extensive sampling of uterine cavity.

The present study is an attempt to demonstrate various causes of AUB in peri and post-menopausal patients by histopathological examination of endometrial curettage and to correlate the clinical presentation with histopathological diagnosis.

\section{Materials And Methods}

A retrospective comparative analysis of 156 cases of AUB in the peri and postmenopausal women was done in the Department of Pathology, ESIPGIMSR \& ESIC Medical College, Kolkata from November'14 to October '15. Data regarding the age and presenting clinical features were retrieved from the accompanying laboratory request forms or patients records wherever available. All data were recorded in a structured proforma. 
For each case, representative slides were reviewed by at least two expert histopathologists and the pattern of uterine histopathological changes identified and classified according to clinical presentation.

Histopathological changes were classified into three broad categories. The first category includes patients with abnormal uterine bleeding due to non-organic causes as mentioned below:

1. Secretory endometrium,

2. Proliferative endometrium,

3. Atrophic endometrium,

4. Disordered proliferative endometrium,

5. Irregular shedding of endometrium

6. Iatrogenic endometrium

The Second Category Includes Patients With Abnormal Uterine Bleeding Due To Organic Causes Like

1. Endometrial polyp

2. Endometritis

3. Endometrial hyperplasia

4. Endometrial carcinoma

The third category includes patients whose specimens were Insufficient for diagnosis Endometrial curettage tissue sample was received in the department of pathology for evaluation. All the specimens were fixed in 10\% formalin, processed and embedded in paraffin, and 3-4 $\mu$ thick sections were made. Sections were stained with Hematoxylin and Eosin stain (H\& E).

\section{Results}

A total of 156 perimenopausal and postmenopausal women presenting with abnormal uterine bleeding underwent endometrial sampling at ESI-PGIMSR \& ESIC Medical College, Kolkata over a period of one year. The most common clinical presentation was menorrhagia (43\%) followed by metrorrhagia (21\%), postmenopausal bleeding (15\%), menometrorrhagia (12\%) and polymenorrhea (9\%).(Figure 1)

Histopathological diagnosis was possible in 151 patients with inadequate sample material in the rest 5 cases. Among the diagnosed 151 patients, 121 patients of abnormal uterine bleeding is due to non-organic causes of the endometrium comprising $80.1 \%$ of total while in the rest 30 cases $(19.9 \%)$ definite organic pathology was found.

Non-organic causes: Out of the 121 non-organic causes of AUB, normal physiological changes like secretory, atrophy and proliferative endometrium were most common and seen in 52 cases(42.9\%), 25 cases $(20.7 \%)$ and 24 cases(19.8\%) respectively. These are followed by iatrogenic endometrium $(8.3 \%)$, disordered proliferative endometrium (5.0\%) and irregular shedding of endometrium (3.3\%).

Organic Causes: Among the organic causes of endometrium, different lesions found were endometrial polyp in 13 cases $(43.3 \%$ ), endometrial hyperplasia without atypia in 8 cases(26.7\%), endometrial carcinoma in 7 cases $(23.3 \%)$ and endometrial hyperplasia with atypia and granulomatous endometritis both in 1 case $(3.3 \%)$ each. A total of 7 cases of endometrial carcinoma were found with different variable histo-morphology like endometrioid $(n=4)$, serous papillary $(n=2)$ and undifferentiated carcinoma $(n=1)$.

When clinical presentation was correlated with histopathological diagnosis, menorrhagia, the most common presenting complaint, showed secretory pattern of endometrium in 24 cases $(36.9 \%)$ followed by atrophic in 11 cases $(16.9 \%)$, proliferative in 9 cases $(13.9 \%)$, endometrial polyp in 8 cases $(12.3 \%)$, iatrogenic endometrium in 7 cases(10.8\%), irregular shedding and hyperplasia without atypia each in 2 cases(3.1\%), disordered proliferative endometrium and granulomatous endometritis each in 1 case $(1.5 \%)$.

Secretory pattern was also most common pattern in patients presenting with metrorrhagia and menometrorrhagia comprising $50 \%$ and $38.9 \%$ of the total cases respectively.

Endometrial hyperplasia and carcinoma together was seen in $38.9 \%$ cases of menometrorrhagia. Proliferative phase of endometrial cycle is the most common(35.7\%) histopathological finding in polymenorrhea while atrophic endometrium is seen in $31.8 \%$ of post menopausal bleeding. 
A Study On Histopathological Patterns of Endometrium In Different Types of...

Table 1- Histopathological findings in different types of abnormal uterine bleeding

\begin{tabular}{|c|c|c|c|c|c|c|c|c|c|c|c|c|c|}
\hline \multirow[t]{5}{*}{ Clinical feature } & \multicolumn{6}{|c|}{ Functional causes $(n=121)$} & \multirow{2}{*}{\multicolumn{5}{|c|}{ Organic causes $(n=30)$}} & & \\
\hline & & & & & & & & & & & & No & Total \\
\hline & \multirow[t]{3}{*}{$\mathrm{Sec}$} & \multirow[t]{3}{*}{ Pro } & \multirow[t]{3}{*}{ Atr } & \multirow[t]{3}{*}{ D.p. } & \multirow[t]{3}{*}{ I.sh } & \multirow[t]{3}{*}{ Iat } & \multirow[t]{3}{*}{ Gran } & \multirow{3}{*}{$\begin{array}{l}\text { Poly } \\
\mathrm{p}\end{array}$} & Hypr & Hypr & \multirow[t]{3}{*}{ Car } & Opinion & \\
\hline & & & & & & & & & $\begin{array}{l}\text { Withou } \\
\mathrm{t}\end{array}$ & With & & & \\
\hline & & & & & & & & & Atypia & $\begin{array}{l}\text { Atypi } \\
\text { a }\end{array}$ & & & \\
\hline menorrhagia & 24 & 9 & 11 & 1 & 2 & 7 & 1 & 8 & 2 & 0 & 0 & 2 & 67 \\
\hline metorrhagia & 16 & 5 & 3 & 2 & 1 & 2 & 0 & 2 & 1 & 0 & 0 & 1 & 33 \\
\hline menometorrhagia & 7 & 1 & 1 & 1 & 0 & 1 & 0 & 0 & 2 & 1 & 4 & 0 & 18 \\
\hline polyp & 2 & 5 & 3 & 1 & 1 & 0 & 0 & 1 & 1 & 0 & 0 & 0 & 14 \\
\hline Postmenopausal & \multirow[t]{2}{*}{3} & \multirow[t]{2}{*}{4} & \multirow[t]{2}{*}{7} & \multirow[t]{2}{*}{1} & \multirow[t]{2}{*}{0} & \multirow[t]{2}{*}{0} & \multirow[t]{2}{*}{0} & \multirow[t]{2}{*}{2} & \multirow[t]{2}{*}{2} & \multirow[t]{2}{*}{0} & \multirow[t]{2}{*}{3} & \multirow[t]{2}{*}{2} & \multirow[t]{2}{*}{24} \\
\hline bleeding & & & & & & & & & & & & & \\
\hline Total & 52 & 24 & 25 & 6 & 4 & 10 & 1 & 13 & 8 & 1 & 7 & 5 & 156 \\
\hline
\end{tabular}

$\mathrm{Sec}=$ secretory, pro=proliferative, atr= atrophic, d.p.=disordered proliferative, I.sh=irregular shedding, iat=iatrogenic, gran=granulomatous endometritis, hypr= hyperplasia, car= carcinoma

\section{Discussion}

The term abnormal uterine bleeding has been used to describe any bleeding not fulfilling the criteria of normal menstrual bleeding. The causes of abnormal uterine bleeding include a wide spectrum of diseases of the reproductive system and non-gynecologic causes as well. When an organic cause of AUB cannot be found, then by exclusion, a diagnosis of dysfunctional uterine bleeding (DUB) is assumed.

Perimenopausal patient $(n=132)$ in the age range of $41-50$ years presenting more commonly with AUB as compared to post menopausal $(n=24)$.This corroborated well with studies by Sajitha $\mathrm{K}$ et al ${ }^{6}$ and Vaidya $\mathrm{S}$ et $\mathrm{al}^{7}$. Various pattern of AUB seen in this patients is mainly because of fluctuation in the estradiol level as there is decline in ovarian follicles and cycles become anovulatory. Now a days because of increased awareness amongst patients as well as better evaluation techniques, patients could be evaluated much earlier. Hence increased number of perimenopausal patients with AUB is observed in the present study.

Most common complain found in the present study is mennorrhagia (46.2\%) which is close to incidence reported by Sajitha K et al. $(34.4 \%){ }^{6}$ They opined that the defect is in the control process regulating the volume loss during menstrual break down of endometrium which in turn leads to regular episodes of heavy menstrual blood loss. In $80.1 \%$ cases ,AUB occurred because of functional causes as compared to $19.9 \%$ where organic causes was found.

\section{Functional causesof AUB}

On histopathological examination of endometrial curettage from patients of AUB in the present study, secretory pattern followed by atrophic and proliferative endometrium were the common findings with prevalence of $33.3 \%, 16 \%$ and $15.3 \%$ respectively. Similar observation was made in the studies of Vaidya $\mathrm{S}$ et $\mathrm{al}^{7}$ and Sajitha $\mathrm{K}$ et $\mathrm{al}^{6}$. The bleeding in secretory phase is due to ovulatory dysfunctional uterine bleeding and the main defect is in the control of processes regulating the volume of blood lost during the menstrual breakdown of endometrium. Thus bleeding is characterized by regular episodes of heavy menstrual blood loss or menorrhagia. ${ }^{8}$

Atrophic endometrium is the most common cause of abnormal uterine bleeding in postmenopausal stage in our (7 out of $24 ; 29.2 \%)$ as well as in other study. Incidence of atrophic endometrium in post menopausal patients varies from $4.34 \%-36.2 \% .^{9-10}$. Thin walled veins, superficial to the expanding cystic glands, make the vessels vulnerable to injury and lead to excessive uterine bleeding. This apparent higher incidence of atrophic endometrium in our study is due to the fact that our study population includes only $\geq 41$ years aged patient instead of any age.

Proliferative endometrium is found to be almost equal in frequency with atrophic endometrium in our study (24 cases; 16.5\%).Other studies reported incidences of $33 \%, 32.6 \%$, and $32 \% .{ }^{11-13}$ This pattern was commonly observed in the late reproductive and perimenopausal women due to the hormonal imbalance in this group leading to intermittent anovulatory cycles. As our study includes only peri and post menopausal women in contrast to other studies our incidence of proliferative endometrium is seemed to be lower.

In our study, pill endometrium is seen in $10(6.6 \%)$ cases. In other studies its incidence was lower and varied from $1.7 \%-4.81 \% .{ }^{14-17}$ As this pattern is predominantly seen in the perimenopausal age group, our study reveals a relatively higher incidence. This is probably due to the fact that increased number of patients in this age usually seek for early medical management for bleeding. 
Disordered proliferative pattern lies at one end of the spectrum of proliferative lesions of the endometrium that includes carcinoma at the other end with intervening stages of hyperplasias. It differs from the normal proliferative endometrium in the absence of uniform glandular development but is not abnormal enough to be considered hyperplastic . Disordered proliferative patterns resembles a simple hyperplasia, but the process is focal rather than diffuse. In this study, $6(3.9 \%)$ cases are diagnosed while in the literature its incidence varies from $5.7 \%$ to $20.54 \%$. Similar to other studies, it is more common in the $41-50$ age group. ${ }^{15,18-19}$ Diagnosing the patients at the earliest stage of this spectrum will be of definitive help to the practicing gynaecologists to prevent the disease progression.

Irregular shedding of the endometrium is apparently due to slow degeneration of the corpus luteum with prolonged exposure of the menstruating endometrium to the waning progesterone. Clinically, irregular shedding of the endometrium manifests itself by cyclic prolonged menstruation, which may be profuse. In our study total number of cases with irregular shedding of endometrium was found in $4(2.6 \%)$ cases and none of them are post menopausal.

\section{Organic causes of AUB}

In $19.9 \%$ of patients AUB was the result of a well-defined organic lesion. Prevalence of benign polyp in the present study is $8.6 \%$ and majority of them (11 out of $13 ; 84.6 \%)$ was in $41-50$ years age group. It is important to diagnose endometrial polyp as it may provide a suitable microenvironment for the development of malignancy.

The second most common organic cause of AUB was found to be endometrial hyperplasia in $5.79 \%$ cases. However higher incidence was reported by Vaidya S et al $(10.94 \%)^{7}$ and Muzaffar M et al $(24.7 \%)^{14}$ with peak in perimenopausal age group. The possible explanation could be that most of patients here belong to lower socioeconomic status and the occurrence of risk factors like obesity, diabetes, increased intake of animal fat and sedentary life style is low. In the absence of ovulation and the production of progesterone, the endometrium responds to estrogen stimulation by proliferation. This endometrial proliferation with no periodic removal leads to the rupture of the fragile endometrial tissue and irregular bleeding. As endometrial hyperplasia is a precursor of endometrial cancer, with overall risk of progression to cancer being $5-10 \%,{ }^{15}$ its identification is important in peri and postmenopausal patients presenting with AUB.

In the present study $4.6 \%$ cases were diagnosed as endometrial carcinoma on histopathological examination of endometrial curettage in patients presenting with AUB(7 out of 151).Almost similar observation was made by Vaidya $\mathrm{S}$ et al $(3.6 \%)^{7}$ and Mencalgia L $(4.4 \%){ }^{20}$ Endometrioid carcinoma followed by papillary serous and an undifferentiated carcinoma were the variable histological types found. The most common presentation in these patients are menometrorrhagia followed by post menopausal bleeding. Incidence of endometrial carcinoma was $22.2 \%$ (4 out of 18) in the menometrorrhagia group and $13.6 \%$ (3 out of 22) in the diagnosed postmenopausal group. This was somehow lower to that reported by Dangal G in Chitwan in 2003 $(17.6 \%)^{21}$

Another benign organic lesion found is 'granulomatous endometritis' compatible with tubercular etiology showing caseating granulomas with epitheloid cells and Langhans giant cells. In a large study of proven cases of tuberculosis of the endometrium reported bleeding as a presenting symptom in $22.2 \%$ cases. $^{22}$

In $3.2 \%$ (5 out of 156 ) cases, the endometrial specimens labelled unsatisfactory for reporting showed scant amount of fragmented glands and stromal tissue and vast areas of haemorrhage. A study which evaluated the negative predictive value of inadequate endometrial samples in diagnosing endometrial hyperplasia and malignancy suggested that an inadequate endometrial sample may be sufficient to rule out endometrial neoplasia because of its high negative predictive value. ${ }^{23}$

Table 2- comparison of different studies

\begin{tabular}{|c|c|c|c|c|}
\hline & Devi J et al ${ }^{10}$ & 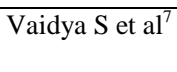 & Ghani NA et $\mathrm{al}^{24}$ & $\begin{array}{l}\text { Present } \\
\text { study }\end{array}$ \\
\hline \multicolumn{5}{|l|}{ FUNCTIONAL CAUSES } \\
\hline Proliferative & $25.4 \%$ & $18 \%$ & $13.75 \%$ & 15.3 \\
\hline Secretory & $4.6 \%$ & $20 \%$ & $10 \%$ & 33.3 \\
\hline Iatrogenic & $0.6 \%$ & $04 \%$ & $05 \%$ & 6.4 \\
\hline Disordered proliferative & $3.6 \%$ & $12.8 \%$ & - & 3.8 \\
\hline Luteal phase defect & - & $0.8 \%$ & - & 2.6 \\
\hline Atrophic & $36.2 \%$ & $7.6 \%$ & $1.25 \%$ & 16 \\
\hline \multicolumn{5}{|l|}{ ORGANIC CAUSES } \\
\hline Endometritis & $1.2 \%$ & $3.6 \%$ & $05 \%$ & 0.64 \\
\hline Polyp & $2.2 \%$ & $1.6 \%$ & $12.5 \%$ & 8.3 \\
\hline Hyperplasia & $18.8 \%$ & $12.8 \%$ & $42.5 \%$ & 5.7 \\
\hline Carcinoma & $0.6 \%$ & $3.6 \%$ & $2.5 \%$ & 4.4 \\
\hline Inadequate & $6.8 \%$ & $6.8 \%$ & $3.75 \%$ & 3.2 \\
\hline Weakly proliferative & - & $8.4 \%$ & - & - \\
\hline Decidual reaction & - & - & $3.75 \%$ & - \\
\hline
\end{tabular}




\section{Conclusion}

Atypical uterine bleeding in peri and postmenopausal women is most commonly dysfunctional in origin. In addition, endometrial hyperplasia and carcinoma together also constitute a significant proportion of cases among the organic causes, thereby highlighting the importance of endometrial curetting and biopsy as a diagnostic procedure in the evaluation of abnormal uterine bleeding in peri and post menopausal age group to exclude preneoplastic and neoplastic conditions. Another interesting finding is that histopathological diagnosis of hyperplasia and malignancy is maximum in the patients presented with menometrorrhagia followed by postmenopausal bleeding.

\section{References}

[1]. Munro MG, Critchley HO, Fraser IS, FIGO Menstrual Disorders Working Group. The FIGO classification of causes of abnormal uterine bleeding in the reproductive years. Fertil Steril 2011;95:2204-8.

[2]. Albers JR, Hull SK, Wesley MA. Abnormal uterine bleeding. Am Fam Phys 2004; 69:1915-26.

[3]. Thoms SL, Ellertson C: Nauisance or natural and health: should monthly menstruation be option for women? Lanct, 2000;355:9224

[4]. Dangal G. A study of endometrium of patients with abnormal uterine bleeding at Chitwan valley. KUMJ 2003;1:110-2

[5]. Kumar A, Mittal S. Endometrial sampling: How? \& why? Obs and Gynae Today. 2007; 12 (6) :284-87.

[6]. Sajitha K, Padma SK, Shetty KJ, Kishan Prasad HL,Permi HS, Hegde P. Study of histopathological patterns of endometrium in abnormal uterine bleeding. CHRISMED J Health Res 2014;1:76-81.

[7]. Vaidya S, Lakhey M, Vaidya SA, Sharma PK, Hirachand S, Lama S. Histopathological pattern of abnormal uterine bleeding in endometrial biopsies. Nepal Med Coll J 2013; 15(1): 74-77.

[8]. Livingstone M, Fraser IS. Mechanisms of abnormal uterine bleeding. Hum Reprod Update 2002;8:60-7.

[9]. Cornitescu FI, Tănase F, Simionescu C, Iliescu D. Clinical, histopathological and therapeutic considerations in non-neoplastic abnormal uterine bleeding in menopause transition. Rom J Morphol Embryol 2011;52:759-65.

[10]. Devi J, Aziz N. Study of "histopathological pattern of endometrium in abnormal Uterine bleeding in the age group 40-60 years" -a study of 500 cases. International journal of medical science and clinical inventions 2014;1(10): 579-585

[11]. Jesadapatrakul S, Tangjitgamol S, Mausirivitaya S. Histopathologic consistency between endometrial hyperplasia diagnosis from endometrial curettage and pathologic diagnoses from hysterectomy specimens. J Med Assoc Thai 2005;88:S16-21.

[12]. Dangal G. A study of endometrium of patients with abnormal uterine bleeding at Chitwan valley. Kathmandu Univ Med J (KUMJ) 2003;1:110-2.

[13]. Perveen S, Perveen S. Endometrium histology in abnormal uterine bleeding. MC 2011;17:68-70.

[14]. Muzaffar M, Akhtar KA, Yasmin S et al. Menstrual Irregularities with excessive blood loss: a clinico-pathological correlation. J Pak Med Assoc 2005; 55: 486-9.

[15]. Jairajpuri ZS, Rana S, Jetley S. Atypical uterine bleeding - Histopathological audit of endometrium - A study of 638 cases. Al Ameen J Med Sci 2013; 6(1): 21-8.

[16]. Baral R, Pudasaini S. Histopathological pattern of endometrial samples in abnormal uterine bleeding. J Pathol Nepal 2011; 1: 13-16.

[17]. Khare A, Bansal R, Sharma S et al. Morphological Spectrum of Endometrium in Patients Presenting with Dysfunctional Uterine Bleeding. People's J Scientifi c Res 2012, 5: 13-16.

[18]. Doraiswami S, Johnson T, Rao S et al. Study of Endometrial Pathology in Abnormal Uterine Bleeding. J Obstet Gynecol India 2011; 61: 426-30.

[19]. Abdullah LS, Bondagji NS. Histopathological Pattern of Endometrial Sampling Performed for Abnormal Uterine Bleeding. Bahrain Med Bull 2011; 33: 1-6.

[20]. Mencalgia L. Hysteroscopy and adenocarcinoma. Obstet Gynecol Clin North Amer 1995; 22: 573-9.

[21]. Dangal G. A study of endometrium of patients with abnormal uterine bleeding at Chitwan valley. KUMJ 2003;1:110-2.

[22]. Reys, Maheshwri HB. Tuberculosis of the endometrium. A histopathological study of 500 biopsy cases. Ind J Tub 1971;18:27-33.

[23]. Harmanli OH, Shunmugham S, Shen T, Houck KL, Chatwani AJ. The negative predictive value of inadequate" endometrial biopsy in diagnosing endometrial neoplasia. J Gynecol Surg 2004;20:13-6.

[24]. Ghani NA, Abdulrazak AA., Abdullah EM. ABNORMAL UTERINE BLEEDING: A HISTOPATHOLOGICAL STUDY. World Research Journal of Clinical Pathology2012;1:06-08

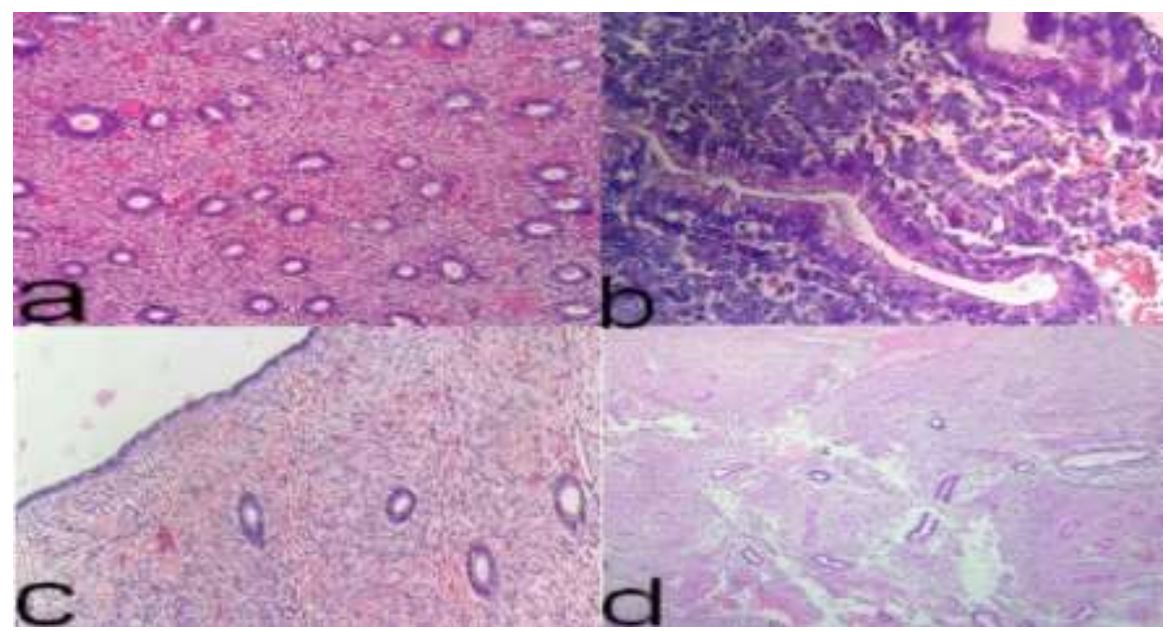

Fig 1- H\&E stained sections show proliferative endometrium(a), secretory endometrium(b), atrophic endometrium $(\mathrm{c})$ and iatrogenic endometrium(d). 


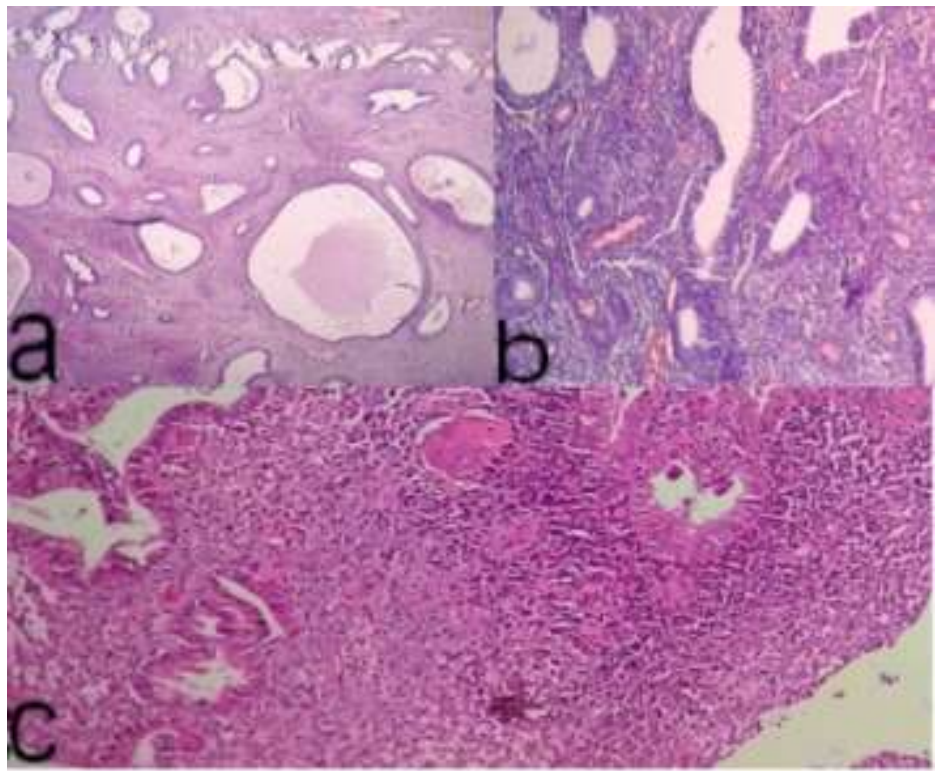

Fig 2- H\&E stained sections show endometrial polyp(a), endometrial hyperplasia without atypia(b) and granulomatous endometritis(c).

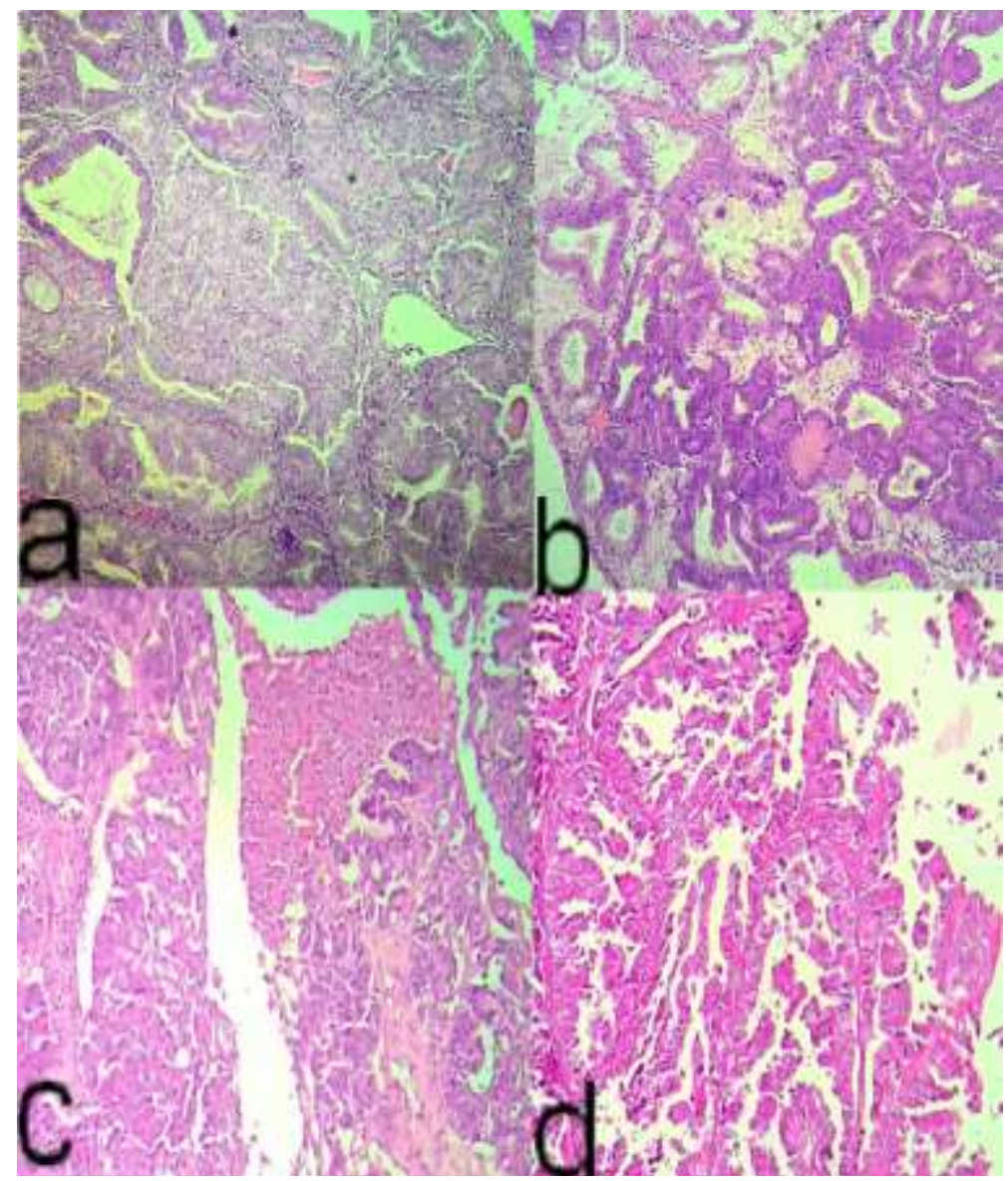

Fig 3- H\&E stained sections show different types of endometrial carcinoma(a-d). 